\title{
Against the Standards: Analyzing Expectations and Discourse of Educators regarding Students with Disabilities in a Kindergarten Classroom
}

\author{
Fernanda T. Orsati \\ Hussman Institute for Autism, 5521 Research Park Drive, Catonsville, MD 21228, USA \\ Correspondence should be addressed to Fernanda T. Orsati; ftorsati@syr.edu
}

Received 27 August 2014; Revised 23 October 2014; Accepted 9 November 2014; Published 7 December 2014

Academic Editor: Jo Lunn Brownlee

Copyright (c) 2014 Fernanda T. Orsati. This is an open access article distributed under the Creative Commons Attribution License, which permits unrestricted use, distribution, and reproduction in any medium, provided the original work is properly cited.

\begin{abstract}
This two-year ethnographic case study critically examines the language educators use to describe students with disabilities who are considered to present challenging behaviors in one classroom. Focusing on the language and practices used by one special education teacher and three teaching assistants, this paper explores how educators respond to students' behaviors by analyzing educators' utterances and the implication of such use for the education of the students. Using critical discourse analysis, this paper highlights how educators' language in the classroom reflects a discourse of expectations that is based on various social standards and pressures that educators have to juggle. Educators expressed academic and behavioral standards by comparing students' performance to the expected norm as well as through comparisons between students. Based on such comparisons, some students were constructed as always lacking and ultimately defined by the adjectives originally used to describe them. Students were perceived to embody defiance or smartness, the characteristics by which they were defined.
\end{abstract}

\section{Introduction}

From a young age, students' behavior and academic achievement are used to determine not just services for which they are eligible but also placement and discipline methods used to respond to their behaviors. Students with more significant needs and who display behaviors that can be understood as disruptive tend to spend less time in general education [1]. The attribution of behavior problems to students, especially students labeled as having a disability, becomes an important issue because it can determine teacher expectations, students' placement, and the quality of education that the student will receive. The judgment of behaviors and what constitutes a behavior challenge, problem, or issue is historically, contextually, and culturally dependent, which means that it is socially constructed [2]. According to traditional special education, students with disabilities and challenging behaviors are believed to embody inherent deficits located in them because they do not comply with school rules, especially the rules established for social environments and relationships in the classroom. In this paper, students' uncompliant behaviors interchangebly labeled behavior issues, behavior problems, challenging behavior, or defiant behavior are understood as a social construct. The present study critically examines the informal labeling of students with disabilities based on their behaviors in a kindergarten classroom and its consequences for their education. The literature review will provide an overview of current practices in kindergarten education, the prevailing deficit approaches in special education to understand disability and behaviors, its implication for practices in schools, and how disability studies as a theoretical framework can provide a different perspective for the classroom.

\section{Literature Review}

2.1. Current Issues in the U.S. Kindergarten Education. Numerous changes have occurred within kindergarten and early education over the past years [3-5]. Since kindergarten was first established in U.S. public schools (in 1873) the proportion of students matriculated in these classrooms has grown significantly. Almost every child in the U.S. attends 
kindergarten [4]. With this growth, researchers, practitioners, and policy makers in the area try to balance a traditional approach in which kindergarten is a social transition for children into school and respond to concerns about academic preparation, increased structure, and attention to skill development [4].

Russell [5] provided a complex historical understanding of kindergarten education describing a shift from a developmental logic to an academic one; public discourse "progressively recast the purpose of a kindergarten education from a vehicle for young children's development to the foundation for the individual child's future academic achievement" ([5], p. 256). Self-guided, constructivist, and playful learning now coexist with testing and standardized teaching practices.

The construction of early learning and young children's capabilities has been significantly influenced by No Child Left Behind (NCLB) in defining the "right time" for reading and pressuring "schools to prepare children for testing [because] by beginning the first-grade reading curriculum in kindergarten, schools have effectively gained an extra year of instruction" ([3], p. 30). Educators are inserted into these discourses and, at the same time, continue to juggle school pressures, theories, students' needs, curriculum, adaptations for students with disabilities, and a variety of other factors that influence their everyday practices and the educator-student relationship.

In addition, inclusive and diverse environments have been more prevalent and encouraged in early education [69]. It is important, then, that teachers are prepared to meet the needs of students with disabilities [8]. In these contexts teachers also need to find a balance between establishing a curriculum-based kindergarten that fits into an academically driven school setting, while still providing space for students to develop their skills [9]. Inclusion cannot be accomplished by simple placement of students with disabilities with their typically developing peers [7]. Teachers need to design activities to ensure the full participation of all students while still meeting standards for performance. The current understanding of disability by special education professionals determines the practices in the classroom and as a consequence the education of the children labeled as having a disability. Next section explores the approaches to disability in a special education context.

2.2. Deficit-Driven Approach to Special Education. Practices in special education prioritize the labeling of differences as deficits and disability in order for students to receive services under Individuals with Disabilities Education Act [10]. Power relations are explicit in the use of language and labels because they relegate to the professional the power to make use of deficit concepts to describe a student. Linguistic conventions structure the meetings assigned to disability, and these meanings determine patterns of response to individuals through the process of labeling [11]. Besides its large use, the use of labels lacks any particular benefit or merit for people with disabilities [12].

Labeling in special education is a subjective process that has undergone major changes. For example, the use of terms as moral imbecility, incorrigibility, miscreance, and delinquency were once used to describe the disability label currently named as emotional disturbance. Such changes are important to demonstrate the subjectivity and fluidity of disability as a behavior construct, as well as the change of medical, social, psychological knowledge and perceptions over time [13].

The social professions in modern societies have the "authority to interpret normality and, thus, the power to define and classify others as abnormal" subjecting their bodies and minds to investigation, surveillance, and treatment ([14], p. 41). These processes are not generated by the professionals' intentions; instead, "they reflect a set of social beliefs and values, political agendas, and historical events that combine to construct identities that will become the official version of who these children are" ([15], p. 7). Labeling determines the practices, which in turn determine students' educational trajectory.

Unpacking power and oppression of people with disabilities in language and school practices should allow for the understanding of the role that education plays in reproducing social inequity. As Hehir [16] wrote, "inordinate segregation, low expectations, failure to provide accommodations, and misguided attempts to "cure" disability are all examples of practices that serve to keep disabled students in a subordinate position" (p. 42). These practices are implied in the everyday routines of classrooms and remain unexamined by most educators.

Disability studies unpack oppression by providing perspectives on issues and problems in education and society as defined by individuals with disabilities themselves [17]. From a disability studies framework scholars attend closely to understandings of behavior and behavior problems in special education [18, 19]. Danforth's work analyzed how typically "unwanted behavior" is placed squarely within the individual and considered a pathology. Compliance tend to be the ultimate goal of school practices, instead of an understanding of the individual. The present paper uses a disability studies framework to understand disabilities and behaviors.

Other scholars show the importance of ethnographic studies for unpacking year-long processes of labeling in schools. Hatt's work [20] exhibits how the construction of students' identities relates to understandings of smartness within a kindergarten classroom. Students who maintained docile bodies, as well as those who modeled authority figures, were the ones considered smart by the end of the year. Her findings suggest that smartness operated as a "tool of social positioning, [which was] authoritatively used to denote which students had social power" (p. 455).

Collins [21, 22] described how labels influence teachers' expectations and responses toward students, which impact students' performance. Low expectations and a description of the student based on a disability label, without paying attention to students' objective behavior, generated less investment and practices used by the teacher to support the student. As a consequence, teacher judgment based primarily on the label determined students' performance and learning.

This use of behavior categories, judgments, labeling of behaviors, and other language use (based on deficits) bears 
closer examination. A deficit approach is prevalent in special education, and the outcomes for practice of such discourse need to be further explored. This study examines the following research question: This study examines these following research questions: What are the discourses used by educators in regard to students with disabilities that present behaviors? What are the implications of such discourses to educators' practices in responding to students in a kindergarten classroom? The next section delineates the methodology employed to respond to this question.

\section{Methodology}

This research is an ethnographic case study of Ms. Elmwood's kindergarten classroom: a 20- to 21-student class supported by three teaching assistants. Ethnography is characterized by its emphasis on first-hand fieldwork, participant observation, and a more prolonged time spent in the field [23, 24]. Over the course of a year, data collection was based mainly on participant observation but also included formal and informal interviews with the teacher and teaching assistants. The unit of analysis is the classroom. Within this unit, the analysis focused on the interactions among students, the teacher, and the teaching assistants to address relationships between (a) teacher discourse on students' behaviors, (b) teaching practices to respond to students' behaviors, and (c) students' behaviors.

3.1. Setting and Participants. This kindergarten classroom was located in a suburban area in the Northeast of the United States. The classroom consisted of a half-day segregated classroom and half-day inclusive classroom. In both the 2010-2011 and 2011-2012 school years, ten students were identified as having a disability and remained in this classroom for the full day. After lunch, the classroom received students who were not labeled as having a disability and it was considered by the administration as an inclusive classroom.

The inclusion criterion incorporated teachers who were self-identified as having one or more students with disability as presenting challenging behaviors in their classroom. As a consequence, this research is concerned not only solely with educators' responses to students with the educational diagnosis based on Individuals with Disabilities Educational Act (IDEA) [10] of emotional and behavioral disorder but also with students perceived by teachers as presenting challenging behavior and its intersections with different disability categories as autism and intellectual disabilities, for example. The research participants were four educators: one special education teacher, Ms. Elmwood and three teaching assistants (TAs), Ms. Nelson, Ms. Riley, and Ms. Thompson (all the names in this paper were changed to protect participants' identity). The educator participants' ages ranged from 44 to 67 , and they had 9 to 20 years of experience in schools. The focus of data collection was on the practices that the adults used in relation to students including teaching practices, responses to behavior, and behavior management. The four participants received an explanation about the research and
TABLE 1: Participants' demographic characteristics.

\begin{tabular}{lccc}
\hline $\begin{array}{l}\text { Participant } \\
\text { name }\end{array}$ & $\begin{array}{c}\text { Role in the } \\
\text { classroom }\end{array}$ & Age & $\begin{array}{c}\text { Years of experience } \\
\text { in that role }\end{array}$ \\
\hline Ms. Elmwood & $\begin{array}{c}\text { Teacher } \\
\text { Teaching } \\
\text { assistant }\end{array}$ & 65 & 20 \\
Ms. Riley & $\begin{array}{l}\text { Teaching } \\
\text { assistant }\end{array}$ & 67 & 9 \\
Ms. Thompson & $\begin{array}{l}\text { Teaching } \\
\text { assistant }\end{array}$ & 52 & 16 \\
\hline
\end{tabular}

signed consent forms. Their demographics are included above in Table 1 .

3.2. Data Collection. The participant observation was conducted once a week, in the 2011-2012 school year, and bimonthly, in the 2010-2011 school year. Each visit lasted for a period ranging from one to six hours. Overall, the researcher spent approximately 320 hours observing Ms. Elmwood's classroom over a two-year period. Data was gathered using handwritten field notes during each participant observation, while the interactions were happening. Any dialogue was recorded verbatim and with quotation marks in the field notes. The choice to use handwritten notes was based on the dynamic nature of the kindergarten classroom, as well as to ensure proximity to students and participants.

In addition to participant observation, formal and informal interviews with the teacher and teaching assistants were conducted. A total of 7 formal interviews were conducted. They ranged from one to two hours; they were audiorecorded and transcribed verbatim.

\section{Analysis}

The analytical framework of this paper is critical discourse analysis (CDA). A basic principle of CDA is that language generates discursive practices and is centrally involved in power and struggles for (or over) power [25]. CDA allowed the understanding of how discursive practices in everyday life create social and cultural reproduction but also how these practices allow for change to take place [26]. The discourse embedded in texts and language generates routine processes of social life and knowledge, including classroom practices. Different authors contribute to a broad understanding of CDA as analytical framework, and in this paper Fairclough [25], van Dijk [27], and Wodak and Meyer [28] are the ones used. However, Gee $[29,30]$ is the methodological approach to the critical discourse analysis itself as performed in this paper.

When a researcher understands language as both discourse and social practice one is committing to an analysis between texts, processes, social conditions, and "both the immediate condition of the situational context and the more remote conditions of institutional and social structures" ([25], p. 21). CDA is a multidisciplinary and issue-oriented approach, mostly relevant when critically examining social inequality and injustice [27]. CDA "is characterized by the 
common interests in the demystifying ideologies and power through the systematic... investigation of semiotic data (written, spoken, or visual)" ([28], p. 3). Established routines in special education are part of a systemic issue that needs to be examined.

Gee's approach $[29,30]$ to critical analysis was the method of analysis employed in this study. Following his general steps, the analysis began with a full reading of all the field notes and interview data organized chronologically. Among all the expressions, words, and sentences used by adults in every day routines this paper explores the ones most representative of educator talk in the classroom when describing students and their behaviors. The steps of analysis were the following. In this first read-through the analyst (a) found recurrent statements, utterances, and sentences present in educators' everyday language. After the first general read-through, she went back to the field notes and interviews and (b) highlighted regularities in utterances found in educator talk that relate to behavior practices, behavior management, and educator response to student behaviors. After all the material was gathered and identified (c) an utterance-type meaning analysis of the most common expressions used by adults in the classroom was undertaken. At this stage, the analyst mapped the relationship between form (morphemes, words, phrases, expressions, and other syntactic structures) and meaning, asking, what function does a specific utterance serve when used by an adult in this classroom?

After the analysis of these utterances by type of word and expression choices was completed, the analyst examined their (d) token-meaning or situated meaning. This analysis revealed the effects of language in everyday practices employed in the classroom. At this stage the question was, what is the effect of the utterance used on classroom practices by adults? Thus, the context in which the adults were using the utterance to respond to behaviors was described.

Discourse and practices seemed to shape how educators identify and respond to students' behaviors in this kindergarten classroom. In the next sections, this paper examines and discusses the utterances, discourses, and practices that compare students with a standard for what is expected for behavior, shows that behavior in kindergarten is closely related to performance, and, lastly, explores the personification of students' characteristics.

4.1. Against the Standards: Expressing Low Expectations for Students. This paper uses a critical perspective to understand the larger social relevance of the simple and subtle classroom language and practices in one kindergarten. A critical perspective was also important to understand teacher, TAs, and students as both the products and producers of discourse. Educators were juggling pressures of the educational system, such as the time constraints of their day in which they were trying to cover the curriculum, in order to get students "ready for first grade." In addition, there is a focus on the results, and, as a consequence, the need to "control behaviors" to be able to fulfill all those demands. Educators employed creative and flexible practices centered on the students' needs. Overall, both students and educators are oppressed and empowered within the discourse.
Ms. Elmwood's classroom was an ample environment with different activity spaces, including areas for students to play, read, engage in activities at tables, and use the computer. In addition, she had a large amount of resources including art materials, manipulatives, games, toys, books, and CDs, to name a few. In this resource-rich environment students and TAs were expected to follow a routine that was established by the teacher. From arriving and putting their backpacks away to lunch time, the morning students' routine included morning work, time on the rug for calendar and for sharing books/stories, activity time at the tables, free playtime, another activity at the tables, and story time back on the rug. After lunch, the morning students had free time to play until their afternoon classmates arrived. The afternoon routine followed the same pattern as the morning, including rug time with calendar and story (which sometimes was repetition for morning students), activities at the table, free time to play, reading groups and/or activity for the whole class, and rug time for story. The routine in the classroom was planned and divided in approximately 25 to 30 minute blocks, so students were expected to transition from one to the next efficiently. This means that students were required to have finished the first activity and be ready to go straight to the next.

Ms. Elmwood planned different modes of instruction throughout the day to reach all students' abilities and preferences. She used songs, videos, drawing, reading books, storytelling, art, and movement, among others. All these activities were structured; the teacher seemed to have a learning goal for each activity, a vision of how they should proceed, and a timeframe for it to be over. The teacher scheduled unstructured moments in the students' routine, which she called playtime periods. She had one playtime period in the morning and one in the afternoon. Therefore, free time or down time during or in between activities was not incorporated into the routine. The three TAs in the room made sure that this routine was followed. Ms. Riley described that "our [the TAs] goal is to ... get them moving along. Keep their difficult behaviors to a minimum..." This sentence shows that students' behaviors were seen as an impediment for the fluidity of the school say, and their primarily task as TAs was to contain these behaviors.

During observation it became clear that as early as kindergarten, the expectations for students' behaviors and academic performance were identified in adults' language. Students' behaviors were usually measured against a standard and educators used negative sentence structures when students were not meeting the performance standards.

The example below shows instances where adults expressed negative expectations toward students.

During circle, Ms. Brooke [a substitute teacher] was trying to get the students' attention and have them raise their hands and not yell out the answers. The kids were not doing what she wanted. They were still saying the answers all at the same time. Ms. Riley said, "They don't get it, they can't do it. It's impossible." 
Ms. Riley showed disappointment, because, for her, students "don't get it" or "can't" raise their hands to answer questions. She places the onus of behavior on students, rather than on the adults who may need to support students in learning the acceptable behavior. In both cases, adults reported that students did not meet expectations without analyzing the level of support provided for students or the appropriateness of the expectation. Neither Ms. Riley nor any of the other adults in this classroom directly taught students to not speak during circle time without raising their hands first and waiting until they were called. The adults held expectations for students but did not provide support for them to meet those expectations, by explicitly modeling behavior for instance. Any problem behavior was located solely as a student's problem. In addition, the students' experiences and current performances were not being validated because there was always this standard of behavioral performance that they were measured against.

Another utterance that marked these expectations was the use of "too." This adverb of degree signified "more than is necessary or useful." Educators used it to contrast with some students' performance. There was always a standard against which students were compared. In the sentence below educators were using "too" as a contrast for what students could not do.

Some of the students were playing counting one digit numbers. Ms. Elmwood said, “Last year's group was too smart for this, but this activity is perfect for this group."

Ms. Elmwood made this comment during morning circle. She compared the whole class with last year's class stating how the activities, appropriate for the students from the current year, would not be so for the students from the year before. However, she implied they were too difficult for this year's group. In the next example, the TA voiced the low expectations she had for one specific student.

Ms. Riley was walking around the computers and supervising the students. She saw what Ron was doing and told him, "This is too hard for you. You should be doing the one with letters. Go over each letter. Go back!"

Ron was not allowed to explore and continue working on the activity because of the TA's perception of him. She stated that an activity with whole words was "too hard for" him, despite the fact that he was doing it. Ms. Riley expressed that aspect aloud and all the kids looked at him at that point. She publicly displayed the low expectations she held for him. He just sat there and waited for her to change back to the activity with single letters.

Another way that adults demonstrated low expectations for students was when they appeared surprised at compliant behaviors and simple decisions made by students. This means that students were capable of making decisions and following instructions, but the adults held such low expectations that resulted in amazement when those behaviors were displayed. The next example shows Ms. Elmwood's response to one of Scott's idea.
Scott was leaving the breakfast table and Ms. Riley noticed he had the idea of putting the raisins on the cereal. Ms. Riley complimented his idea. Ms. Elmwood heard and said, "It is indeed a great idea. You have something going on up there; you amaze me sometimes."

Ms. Elmwood's amazement with Scott's decision was again public. With such a statement, she revealed that she did not expect that Scott would have an original idea about anything in the classroom. It is also important to note that his "amazing" idea was not related to academics, but to an everyday life skill. She also stated "you have something going on up there" implying that the student did not; therefore this was not an established expectation for him. Teacher's use of that sentence indicated not only a devaluing of Scott's thoughts, but overall a lack of presuming his competence. The next example reveals the same type of reaction that occurred when a student was checking to see if his performance was accepted, which is also related to the membership discourse pervasive in this environment.

Students were coloring their books. Ms. Elmwood was walking around and making sure students were coloring the right spots with the right colors. A lot of them were not and she was redirecting them. Ms. Thompson came to Nathan's side. Nathan asked, "I'm doing okay, Ms. Thompson?" Ms. Thompson said, "You are! It's a miracle!" Nathan seemed very proud of himself.

Ms. Thompson checked on Nathan's work and he wanted to make sure his performance aligned with the teacher's academic and behavioral expectations. The TA stated with excitement that it was even more than what she expected from him. From her response, it seems that it was a rare accomplishment when Nathan's performance met the standard. In both comments "You have something going on up there" and "It's a miracle" surprise was expressed. All of these expressions were used in the classroom and made publicly and thus were available to be picked up by classmates. They are subtle in a kindergarten environment where there are a lot of interactions and various reactions expressed over the course of even one day. However, these small messages construct the perceptions of who children were as students which influences their future educational trajectories. Some students eventually started picking up on the low expectations, as Ron in the example below.

During circle, Ms. Elmwood had a puzzle in which students had to assemble body parts guided by steps played on a CD. Ron was not able to assemble the parts of the face. He said, "I knew I couldn't do it." Ms. Elmwood announced they were going to do a second time. He said, "I will do it this time." She provided him more prompts and he was able to assemble more pieces. In the end he said, "I can do it!"

Initially, Ron used language borrowed from the low expectation discourse available to describe his performance, 
as seen in the previous passage when he was in the computer. However, with the progression of the activity and Ms. Elmwood's support, he regained his confidence. These examples were important to show the possibility of changing language use within one activity. When adults provided support to students, adults were generally able to adapt their expectations, and students met the standards. In these moments, adults were able to validate students' needs and not be fixated on the predetermined standards: both students and teachers can be empowered.

The language that adults employed during classroom practice was intrinsically linked to students' performance on learning experiences that were matched to academic and behavioral standards; this, in turn, created a parallel discourse around people with disabilities in larger societal contexts. When talking to students, educators showed that their understanding of students' behaviors and academic performance was based not solely on what was happening in the classroom, but rather on the social standards and norms established for them and students begin to learn these standards and norms in kindergarten. The next passage was a conversation with Ms. Thompson during lunch. In this conversation, Ms. Thompson clearly stated her expectations for Harry's future in a larger context.

Ms. Thompson said, while looking at Harry, "I don't want to sound rude or mean, but this drains a lot of money. I, myself, as support, cost 50 [thousand dollars] a year." They don't have enough [money or resources] for the smart and bright [students], the ones who will actually be carrying the future of this country. They cut the high end courses.... AP courses and our kids need that. The real smart ones need that. Like, Harry, maybe he should be in a different program for him, life skills, maybe, because he is not taking anything [away] from kindergarten education. But, like Dave, Alana, and Amelia, they need the attention. They can do something, be something, and be productive. But, Harry? I don't know. I don't want to sound cruel. I don't know. I don't know. Do you know what I mean?

This statement from Ms. Thompson was complex and it was clearly embedded in a discourse in which "smart" students were the ones for whom the resources should be allocated. Outside standards influenced her description of her students. Ms. Thompson claimed the "smart" students as "our" students. This means that the "smart" ones belonged to her and her group, but Harry and other students did not. She stated that students like Harry were not profiting from kindergarten, and, for that reason, should be in a separate program. In her talk, the relationship between low expectations and the concept of a productive citizen for society became direct. Ms. Thompson was invested in this social discourse of expectation for productivity and could not see how Harry could be a productive citizen in the future. She expressed "I do not know" several times, which shows that she was not sure whether her assumptions were correct or even acceptable. Ms. Thompson was embedded in, and she appropriated a deficit discourse that was available. However, she was not sure whether it was being accepted in the conversation with me. Her doubting, but reproduction of such a deficit discourse showed the power of assumptions regarding students with disabilities and expectations for their future in society. The next data section substantiates how this separation between those who were perceived to be productive and those who were not seen to be productive students was based on ability status and compliance of behavior.

\subsection{General versus DK Kids: Use of "Than" and "Even" to Com-} pare Performances. This classroom was considered a developmental kindergarten (DK). In the morning there were ten students with Individualized Educational Programs (IEPs) in the classroom, who participated in a full day kindergarten. In the afternoon ten other students, who did not have IEPs, arrived for a half day kindergarten. Comparisons between the morning group, the students with IEPs, and the afternoon group, those who did not have IEPs, were routinely made. Students without labels of disabilities were the standards to which the other students were expected to behave. Two utterances "than" and "even" were used consistently to establish these comparisons.

Ms. Nelson told me, "What usually happens is that the afternoon kids are the ones that support the morning kids. But this year the afternoon kids, in general, are not advancing faster than the morning ones."

The passage above demonstrated again the establishment of low expectations. Here, the utterance "than" was applied as a comparative conjunction. "Than" was used to indicate the point of departure in a comparison, and it expressed inequality. Ms. Nelson's use of this utterance showed that the afternoon kids were not faster, and thereby not "smarter," in comparison to the morning students. This fact defied her expectations because the morning students were usually held to lower standards in comparison to the afternoon students, due to the fact that they were identified with disabilities and had IEPs.

Another utterance that expressed expectations was "even." It also indicated that educators held low expectations for some students, particularly students labeled as having disabilities. The two passages below exposed this particular use of the word "even."

They were working in centers. Ms. Elmwood said, "Time to change tables. Are you ready? Go to the next center." All students started moving. Nevin was not ready but went to the next table anyway. Ms. Elmwood saw his work was not done and asked him to come back and finish painting. Nevin did not stand up; he started talking under his breath and closed his face. Ms. Riley said, "Even Stephen is rolling" trying to get him to get back to the activity.

All students went to the carpet to do reading. Ms. Elmwood had a book for each student to follow 
along. "I think Laurence and Justin could read it," Ms. Elmwood said. "Even you could do it, Noah."

In both examples "even" was used as an adverb to stress a highly unlikely condition or instance. In the first example, the TA was trying to get a student to do the proposed activity by telling him that the other students, for whom low performance expectations were held, were already doing the activity. In the second case, the students that Ms. Elmwood thought would read were already picked in front of all students. Then she ended up looking for another student, Noah, and told him that "even" he could do it. This comparison was made openly and implied not just low expectations toward Noah, but low expectations toward all other students that were not "even" considered capable of reading. Languagein-use in this classroom clearly stated adult's expectations. This language used to describe students' behaviors ended up describing students as their behaviors. The next section explores the description of students as the behaviors they display.

\subsection{Defiant or Smart: Adjectives That Describe Students Not} Students' Behaviors. The expectations determined for the behaviors have clear connections to how adults informally labeled students. Educators regularly used adjectives not to describe behaviors but to describe students. An example of this was the use of the adjectives "challenge" and "defiant." Both labels expressed how students behaved in relation to what is expected and accepted in this classroom. As a consequence of using adjectives to describe children, students began to embody the characteristics that were assigned by adults, characteristics that constructed students' stories. In the first two examples, Ms. Riley explained the reason she called a student defiant.

Ummm, some of the kids in here are, Stephen is totally defiant as far as "I want the computer, I want the computer," you just have to redirect him constantly to get him away of that whole frame of mind.... You need to do what you are supposed to do, when you're supposed to do it.

Ms. Riley described Stephen, the student, and not his behavior, as defiant. She identified him as defiant due to the fact that he did not want to follow the process of control established for the classroom. He wanted to go straight to the computer and just stay there, not leaving to get back to the other activities. The following example shows Ms. Elmwood talking about another student in an interview excerpt.

Noah... he is so oppositional defiant I mean, he sat here for hours and did not do his work, just sat here.

In this last example, as in the previous one from Stephen, educators explained that they believed students to be defiant. It is important to note that oppositional defiant disorder is a medical diagnosis, but none of these students have this disability label. This was due to them not displaying the behavior adults asked or expected. However, even being able to describe the reason for the behaviors, they did not call students' behaviors defiant, but that was what they called the students themselves. These descriptions were used on a regular basis. This paper reproduces the discourses that educators use, so as a consequence, person first language is not used when describing the data. The use of the adjectives to describe the students provided was the process that happened in this classroom, students embodied the characteristics that previously just described them. This meant that the label of defiant would be attached to the student, so the student would be seen through the lens of this description. This language was also used to describe the classroom as a whole. Both examples below are from interviews with the teacher and one of the TAs, and they demonstrate the use of the word defiant in describing students.
Ms. Elmwood, "This group was also oppositional defiant (laugh) to the extremes; even more so with the regular kindergarteners. I had quite the group of children that just were oppositional. I still cannot even to the very last day get them to find their spots, sit down, and get ready for me. They still don't do it."
Ms. Thompson, "I mean, Nathan, umm he is def- initely a defiant kid, he is low intellectually, umm. But he is getting better with what we are doing with him.... Stephen is brain-damaged and has wonderful parents, so, and defiant, very defiant and very stubborn. And we have some ones that have, ah, defiance, we do not have any autisms this year which is shocking, um, but a lot of defiance. You see a lot of OCD in there, you know, where they have to do certain things."

When, in these last two examples the adults used the adjective defiant, they implied students' internal motivation for the behavior, an embodiment of the characteristic, or a definition of the student as the characteristic. The descriptions below show this intentionality implied when Ms. Nelson was describing the students.

Ms. Nelson, "He [Dave] could use some help because he is still oppositional. He's always on the verge of doing the wrong thing. If you see, he is always deciding what he is going to do."

In the example above Ms. Nelson was talking about how Dave improved, but in the end "He is still oppositional." The embodiment of the characteristic in the student was very clear in this example. He "is" oppositional; he was not simply expressing oppositional behaviors. This sentence structure reflects state of being, again intrinsic to the child. For that reason, despite his improvement, Ms. Nelson was saying he could always do the "wrong thing." She saw the student label before seeing the student's actions.

Labels were then attached to who students were in the classroom and determined teacher responses to them. When adults assumed that a student's behavior was intentional, they took it personally. For that reason, adults expressed their 
discomfort when certain students were present in the classroom and relief when they were not. The two passages below provide these examples.

Ms. Nelson said in an interview, "I think my biggest worry when I come here, my biggest heart palpitations come from when I have to handle Nathan 'cause he's so, because he's so defiant."

Ms. Thompson commented on Scott, "You know, we enjoy when he doesn't come, we get aggravated when he is here. He's really defiant lately. He gets angry when he's not being called to do things. You will see if he comes."

In both of these comments, the TAs were talking about how Nathan and Scott's presence made them uncomfortable and that generated their responses to students in a detrimental cycle of language and behavior.

The same kind of embodiment happened in relation to having acceptable performance. When students were understood as "smart," teachers' actions and feelings reflect this approbation. Being smart or recognized as such was related to following the rules and being compliant. Students who did not comply with the behavioral expectations and controls imposed in the classroom were understood as defiant. On the other hand, students who followed the controlled routines were the smart ones. The next example evidences how students were praised with the word "smart" for being on task.

Ms. Elmwood was stating, "Look up here, pay attention to the book." When they looked at her, she pointed her fingers in each student's direction and said, "Oh, Neil you are so smart! Oh Ron, you are so smart! Mike, smart! Nevin, smart!"

Mike was doing the gluing activity very fast and Ms. Elmwood tells him, "Beautiful work, you're smart."

In the first passage, the students, who were on task, were called smart, with the intent to attract more students to be on task. "Smart" was used as an adjective to praise students for their behavior. Being smart, equals being a compliant student in this classroom. Compliance produced a reward from the educator. Smart is a powerful adjective in education and functions as praise for behavior. In the second example, the fact that the student performed the activity fast and his final product was "beautiful" gave him the designation "smart." Both examples indicated that students embodied being smart when their behavior or the product of their behavior was accepted in the classroom. Such language was routinely used and influenced students' and adults' perceptions of other students and responses to them. Justin was one student believed to embody "smartness" in this classroom.

Ms. Elmwood was reading the Bug book and asked out loud from the front of the room, "Who is smart? Justin, you're smart, can you remember parts of a bug?" Justin could name some parts of the bug, but not all of them.

In this example, Ms. Elmwood was calling on a "smart" student who would know all the answers. Ms. Elmwood asked aloud "who is smart?" and then proceeded to say that Justin was. She implied that the other students were not. The importance of the adjective "smart" was that it was not solely related to academic performance but was primarily connected with displaying compliant behavior. Once the student was routinely named "smart" he was seen through this lens for most of the behaviors he displayed. When a student embodies being "smart," like Justin, he could have been displaying the same behavior as another student considered "defiant" and while the first did not provoke any consequences, the second did. The following excerpt exemplifies this process:

Students were working in small groups at tables. Each table had paper cut in different shapes, paint, and brushes in the middle for the students to use. All students were manipulating the materials. Ms. Elmwood asked Scott to stop twice. Right after she took the materials out of his reach and said, "I can't leave anything in front of you." At the same time, Justin was manipulating the materials in front of his face, totally off the table, and rubbing them in his mouth. He also dropped all the cards on the floor. No adult said anything.

Because Justin is believed to be smart his behaviors are not corrected or even noticed; he is not a threat; the label precedes the behavior itself.

\section{Discussion}

This paper analyzes the discourse of expectations present on the educators' language. This classroom, as every other one, is a complicated social environment where the interplay of different discourses is translated into educator actions. Educators' actions have consequences for students' behaviors as well as for students' learning. Educators are acting in discourse and their practices emerge from discourse. Therefore, educators are implicated in the construction of behavior challenges and classroom practices, because these practices are embedded in the discourse available for educators to act upon.

The adults expressed academic and behavioral standards by comparing students' performance to the expected norm, as well as through comparisons between students. Adults' expectations were usually determined within classroom structures but usually influenced by larger educational standards, such as readiness behaviors and performances required at kindergarten exit, accountability, special education laws, and teacher training and preparation in behavior management [31, 32]. Based on such comparisons, some students were always lacking and ultimately defined by the adjectives originally used to describe them. They were perceived to embody the characteristics by which they were defined. The language used was subjective and arbitrary [13] but was mostly subordinating and oppressing [16] in the sense 
that it determined the pattern of adult response to students [11]. Adults saw labels first and responded to students based on these labels attached to them, not to a particular behavior displayed [21, 22]. Educators reproduced and were limited by this system in which they established an alienated relationship of production with students [18, 19]. Danforth explains that both sides are alienated when we focus on productivity and students are seen as commodity. Instead of reproducing assumptions, as we saw in the educators' language, particularly in one of the conversations with Ms. Thompson, these adults need to start asking, what does it mean to be productive? What is considered productive? Who is considered productive? Why are we determining productivity in kindergarten? And, who am I to predict the future contribution of any child based on his/her performance in kindergarten?

The language used by adults included use of expressions in the negative form, such as "he doesn't get it" or "can't do it," which defined low expectations for particular students. Adults also expressed larger social standards of expectations $[3,5]$ when they referred to students as not "going far," or when the adults voiced their opinions about the allocation of resources for students with disabilities as taking away from the "smart and bright ones." Outside standards are clear when these direct comparisons and emphasis on performance are elaborated in teacher language. Students' behaviors interfered with maintaining control of the schedule and pacing of the day, and as a consequence interfered with how much content adults could cover, content that students will be assessed later on. Adults in this classroom are juggling different discourses to respond to students' behavior, particularly to increase student productivity without losing playfulness of kindergarten $[4,5]$. The outside standards pressured adults to respond to labels and respond to students that displayed behaviors.

Educators in this classroom are also accommodating and supporting the needs of students with disabilities; however, they are still struggling in how to address students and their behaviors [8] particularly when providing time for students to develop their skills [9] and being positive about students' differences and different paces. For example, educators used "than" and "even" to compare general and special education students. These comparisons were common and demonstrated that some students were the standards and others need to be evaluated against these standards. This informal evaluation went from just comparing students to informally labeling students using adjectives meant to describe their behaviors. For example, "defiant" and "smart" were related to noncompliant or compliant behaviors, respectively, and became permanently attached to individual students to shape how adults responded to them on a daily basis [11]. This process exemplifies the construction of students' identities related to "smart" or "defiant" behaviors in a kindergarten classroom. As in Hatt's work [20], the label of smart was used on students who maintained docile bodies as well as a tool of social positioning in the classroom environment. In reality "smart" was describing different levels of compliant behaviors, and in the end the smart students were the standards of behaviors in the classroom to which the other students were compared.

\section{Conclusion and Implications}

Overall, adults in this classroom judged students' behavior against standards and norms. These standards and norms were never explicitly stated or explained which caused inconsistencies between educators as well as confusion among the students. The subjective judgment of what was acceptable behavior determined following expectations for students' performance. But also, adults' expectations shaped students' performance, which cycled back to expectations toward students: Educator expectation both created and was created based on students' behaviors. The use of language to describe certain students in comparison to others created a separation between groups of students within the classroom. The "smart" students were the ones who produced and performed according to what was expected. On the other hand, describing a student as "defiant" derived from adults' judgment of student's behaviors, such as not following directions or not complying with the control imposed. In the end, these students were considered as not being productive as expected for this environment. Language originally used to describe students became by the end of the year attached to students' bodies and became who students were in this classroom. Thus, this language becomes reality in the classroom because the labels come before the assessment of the behavior and need, so the label determines teaching practices and learning opportunities for students.

The discursive practices used in the classroom have a cyclical influence on how adults talk about students and respond to them and how students behave and perform in the classroom. Based on perceived characteristics and standards of behaviors students were labeled and supported based on such label. Adults in schools need to be careful with this subjective and informal labeling process. They can embrace a disability studies perspective to establish high expectations for all students and provide supports to make sure that students achieve those goals. The data shows that students who receive caring and encouraging support in the classroom are empowered and inclined to show engagement and on task behaviors. When students from an early age hear comments such as they are "going to love this activity" or "you can do this, keep going," they are defined as capable and are motivated to continue performing and learning. Teachers and TAs need to continue to see strengths and hold high expectations for all students. Ultimately this paper shows that the current inclusive kindergarten classroom needs to accommodate different behaviors with a variety of supports and not establish a rigid standard that all students are measured against.

\section{Conflict of Interests}

The author declares that there is no conflict of interests regarding the publication of this paper.

\section{References}

[1] United States Department of Education, 28th Annual Report to Congress on the Implementation of the Individuals with Disabilities Education Act, vol. 2, United States Department of 
Education, 2006, http://www.ed.gov/about/reports/annual/osep/ 2006/parts-b-c/28th-vol-2.pdf.

[2] S. Taylor, "Before it had a name," in Vital Questions Facing Disability Studies in Education, S. Danforth and S. Gabel, Eds., Peter Lang, New York, NY, USA, 2008.

[3] J. S. Curwood, "What happened to kindergarten? Are academic pressures stealing childhood?" Instructor, 2007, http://www .scholastic.com/teachers/article/what-happened-kindergarten.

[4] E. Graue, "What's going on in the children's garden? Kindergarten today," Young Children, vol. 56, no. 3, pp. 67-73, 2001.

[5] J. L. Russell, "From child's garden to academic press: the role of shifting institutional logics in redefining kindergarten education," American Educational Research Journal, vol. 48, no. 2, pp. 236-267, 2011.

[6] S. Devore and K. Russell, "Early childhood education and care for children with disabilities: facilitating inclusive practice," Early Childhood Education Journal, vol. 35, no. 2, pp. 189-198, 2007.

[7] J. Filler and Y. Xu, "Including children with disabilities in early childhood education programs: individualizing developmentally appropriate practices," Childhood Education, vol. 83, no. 2, pp. 92-98, 2012.

[8] M. T. Hughes and D. M. Valle-Riestra, "Experiences of kindergarten teachers implementing instructional practices for diverse learners," International Journal of Special Education, vol. 22, no. 2, pp. 119-128, 2007.

[9] C. G. Litty and A. Hatch, "Hurry up and wait: rethinking special education identification in kindergarten," Early Childhood Education Journal, vol. 33, no. 4, pp. 203-208, 2006.

[10] United States Department of Education, Individuals with Disabilities Education Act (IDEA) 300.8, 2004, http://idea.ed.gov/.

[11] S. Linton, "Reassigning meaning," in The Disability Studies Reader, L. J. Davis, Ed., pp. 161-172, Routledge, New York, NY, USA, 2nd edition, 2006.

[12] P. Smith, Whatever Happened to Inclusion? The Place of Students with Intellectual Disabilities in Education, Peter Lang Publishing, New York, NY, USA, 2010.

[13] R. L. Osgood, The History of Inclusion in the United States, Gallaudet University Press, Washington, DC, USA, 2005.

[14] T. M. Skrtic, Disability and Democracy: Reconstructing (Special Education for Postmodernity), Teachers College Press, New York, NY, USA, 1995.

[15] B. Harry and J. Klingner, Why Are So Many Minority Students in Special Education? Understanding Race \& Disability in Schools, Teachers College Press, New York, NY, USA, 2006.

[16] T. Hehir, New Directions in Special Education: Eliminating Ableism in Policy and Practice, Harvard Education Press, Cambridge, Mass, USA, 2005.

[17] S. Gabel, "Introduction: disability studies in education," in Disability Studies in Education: Readings in Theory and Method, pp. 1-20, Peter Lang, New York, NY, USA, 2009.

[18] S. Danforth, "Disability as metaphor: examining the conceptual framing of emotional behavioral disorder in American public education," Educational Studies, vol. 42, no. 1, pp. 8-27, 2007.

[19] S. Danforth, "Compliance as alienated labor: a critical analysis of public school programs for students considered to have emotional/behavioral disorders," in Disability Studies in Education: Readings in Theory and Method, S. Gabel, Ed., pp. 85-102, Peter Lang, New York, NY, USA, 2009.

[20] B. Hatt, "Smartness as a cultural practice in schools," American Educational Research Journal, vol. 49, no. 3, pp. 438-460, 2012.
[21] K. M. Collins, Ability Profiling and School Failure: One Childs Struggle to Be Seen as Competent, Lawrence Erlbaum Associates, Mahwah, NJ, USA, 2003.

[22] K. M. Collins, "Discursive positioning in a fifth-grade writing lesson: the making of a "bad, bad boy"', Urban Education, vol. 46, no. 4, pp. 741-785, 2011.

[23] R. C. Bogdan and S. K. Biklen, Qualitative Research for Education: An Introduction to Theories and Methods, Pearson, New York, NY, USA, 2007.

[24] T. A. Schwandt, The SAGE Dictionary of Qualitative Inquiry, Sage, Thousand Oaks, Calif, USA, 4th edition, 2007.

[25] N. Fairclough, Language and Power, Pearson Education, New York, NY, USA, 2001.

[26] L. Philips and M. Jorgensen, Discourse Analysis as Theory and Method, Sage, Thousand Oaks, Calif, USA, 2002.

[27] T. van Dijk, "Principles of critical discourse analysis," Discourse and Society, vol. 4, no. 2, pp. 249-283, 1993.

[28] R. Wodak and M. Meyer, "Critical discourse analysis: history, agenda, theory and methodology," in Methods of Critical Discourse Analysis, R. Wodak and M. Meyer, Eds., pp. 1-33, Sage, Washington, DC, USA, 2009.

[29] J. P. Gee, An Introduction to Discourse Analysis, Routledge, New York, NY, USA, 2011.

[30] J. P. Gee, "Discourse analysis: what makes it critical?" in An Introduction to Critical Discourse Analysis in Education, R. Rogers, Ed., pp. 23-45, Routledge, New York, NY, USA, 2011.

[31] L. Darling-Hammond, "Standards, accountability, and school reform," in Facing Accountability in Education: Democracy and Equity at Risk, C. Sleeter, Ed., pp. 78-111, Teachers College Press, New York, NY, USA, 2007.

[32] A. Kohn, Beyond Discipline: From Compliance to Community, Association for Supervision and Curriculum Development, Alexandria, Va, USA, 1996. 

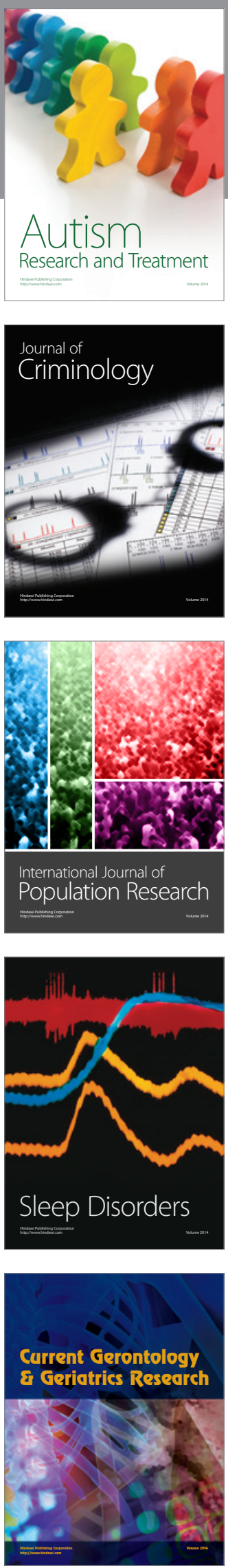
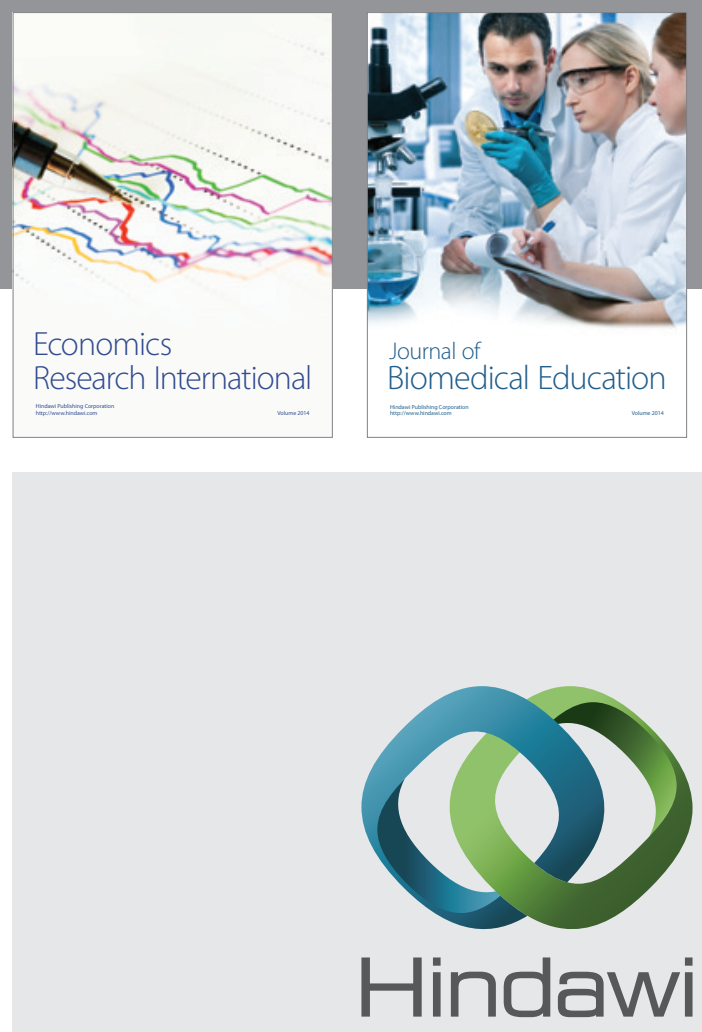

Submit your manuscripts at

http://www.hindawi.com
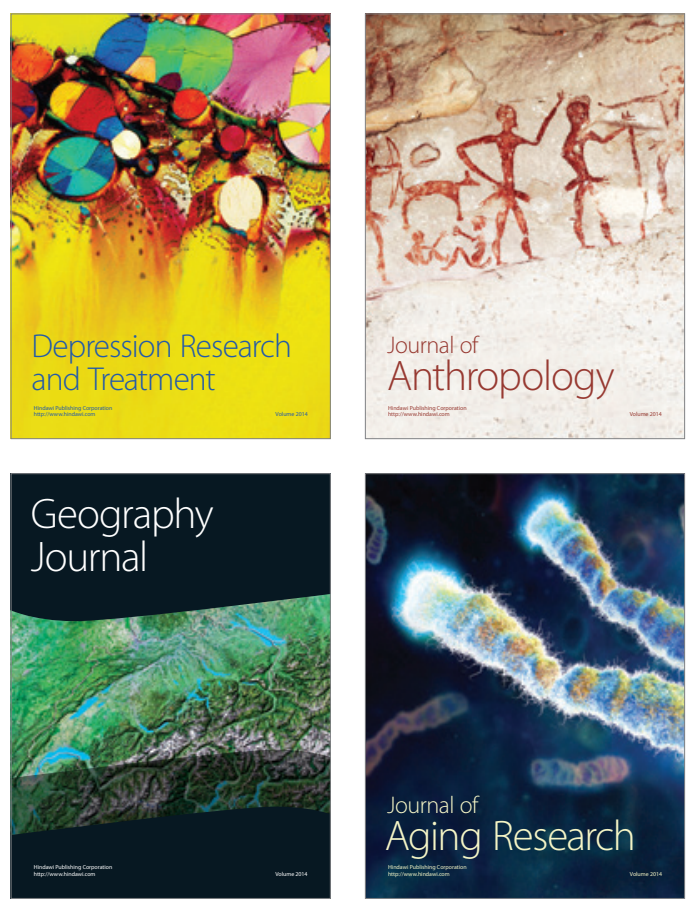
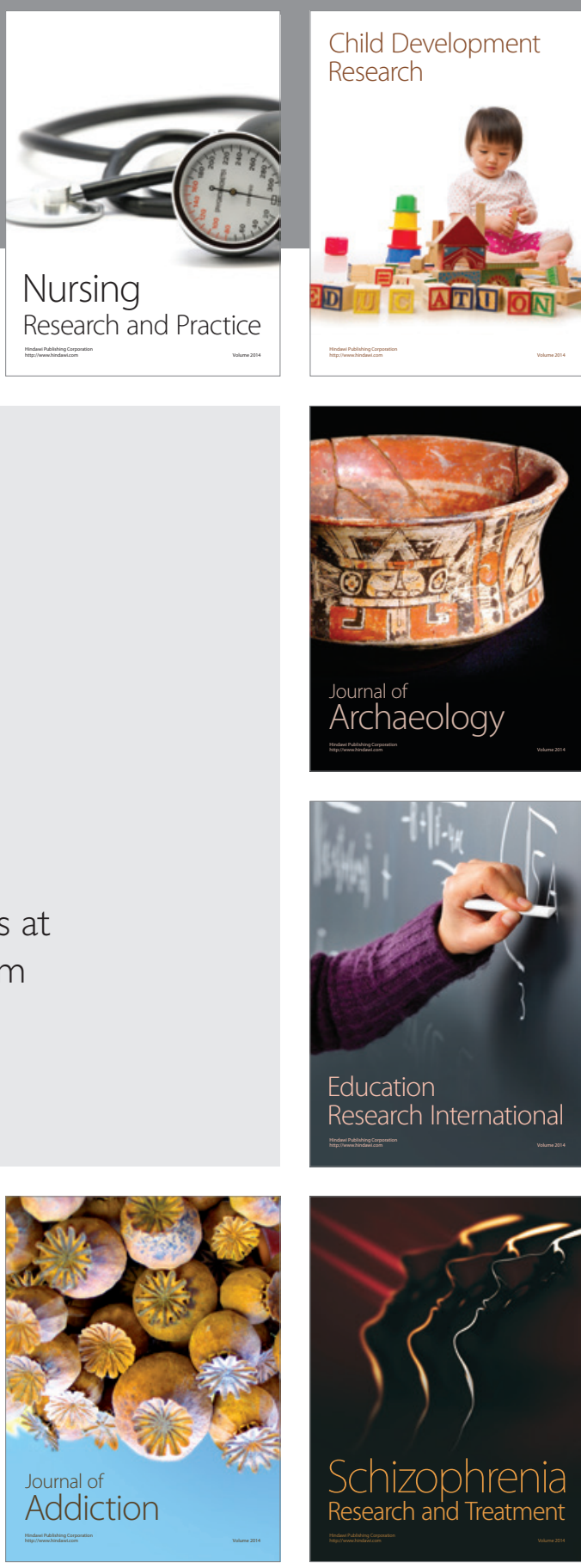

(D)
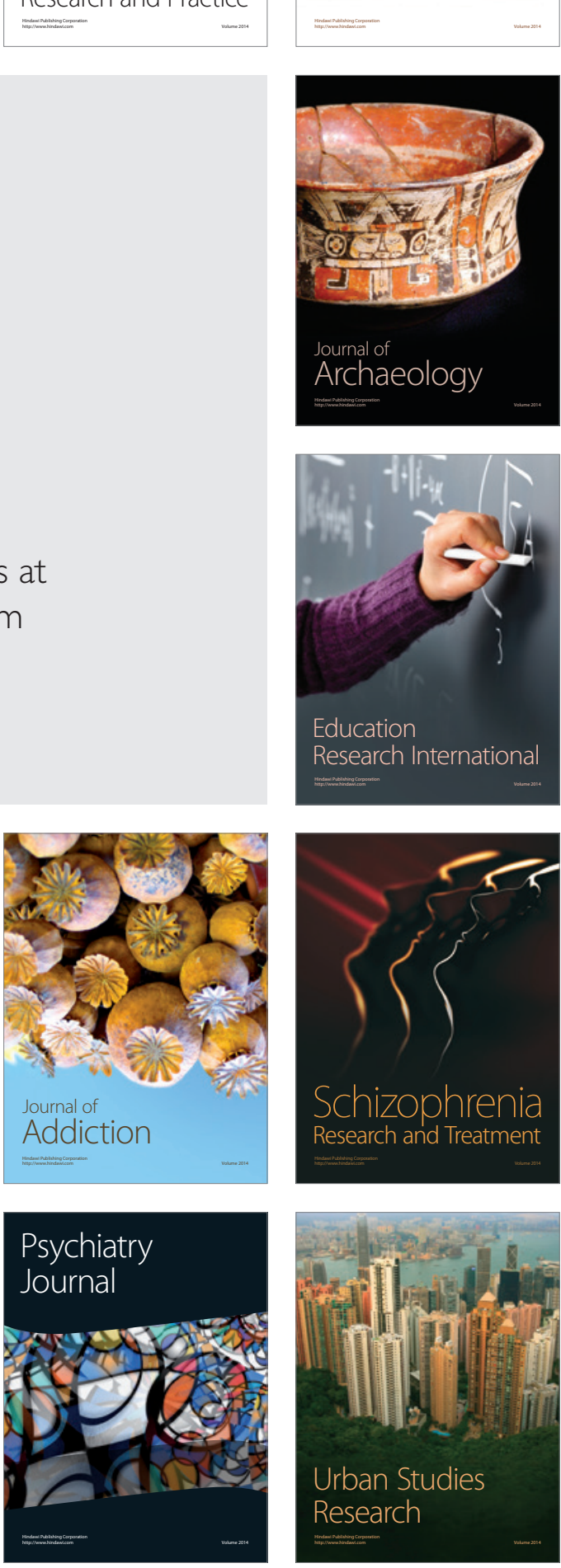